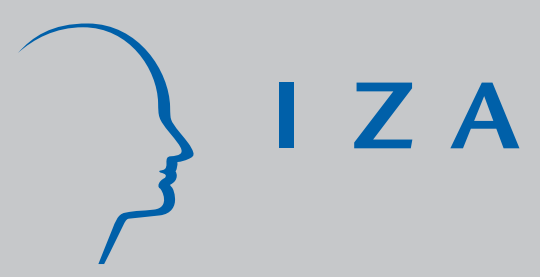

IZA DP No. 2884

Household Division of Labor,

Partnerships and Children: Evidence from Europe

J ose Ignacio Gimenez

J ose Alberto Molina

Almudena Sevilla Sanz

J une 2007 


\title{
Household Division of Labor, Partnerships and Children: Evidence from Europe
}

\author{
Jose Ignacio Gimenez \\ University of Zaragoza \\ Jose Alberto Molina \\ University of Zaragoza \\ and IZA \\ Almudena Sevilla Sanz \\ University of Oxford
}
Discussion Paper No. 2884
June 2007

IZA

P.O. Box 7240

53072 Bonn

Germany

\author{
Phone: +49-228-3894-0 \\ Fax: +49-228-3894-180 \\ E-mail: iza@iza.org
}

\begin{abstract}
Any opinions expressed here are those of the author(s) and not those of the institute. Research disseminated by IZA may include views on policy, but the institute itself takes no institutional policy positions.

The Institute for the Study of Labor (IZA) in Bonn is a local and virtual international research center and a place of communication between science, politics and business. IZA is an independent nonprofit company supported by Deutsche Post World Net. The center is associated with the University of Bonn and offers a stimulating research environment through its research networks, research support, and visitors and doctoral programs. IZA engages in (i) original and internationally competitive research in all fields of labor economics, (ii) development of policy concepts, and (iii) dissemination of research results and concepts to the interested public.
\end{abstract}

IZA Discussion Papers often represent preliminary work and are circulated to encourage discussion. Citation of such a paper should account for its provisional character. A revised version may be available directly from the author. 


\section{ABSTRACT}

\section{Household Division of Labor, Partnerships and Children: Evidence from Europe}

This paper complements conventional economic analysis and presents a social norms interpretation to explain cross-country differences in partnership formation rates, and the dramatic decrease in partnership formation rates in Southern Europe in particular. We argue that increases in female human capital - by raising the opportunity cost of entering a partnership - had a differential impact on partnership formation rates in Northern and Southern Europe due to the different social norms regarding the household division of labor. Social norms are modeled as a constraint on the allocation of household labor that (if binding) diminishes the gains to enter a partnership. Furthermore, highly educated women are less likely to form a partnership, because the utility loss when a partnership is formed is lower the higher the female opportunity cost. We test the predictions of the model using 7 waves of the European Community Household Panel (1995-2001). For each country and year we construct the average of the female to male ratio of childcare time as an indicator of social norms regarding the household division of labor. The empirical findings support the predictions of the model. After controlling for the time and country variation in the data, as well as for permanent individual heterogeneity and other aggregate variables at the country level, the results suggest that more traditional social norms regarding the household division of labor negatively affect a woman's probability of forming a partnership. Thus, a woman living in a country with a more traditional division of household labor has, ceteris paribus, a lower probability of forming a partnership. Furthermore, as predicted by the theory, social norms have a stronger negative effect for highly educated women. To the extent that female education has increased over the years, and that Southern European countries have more traditional social norms, this latter finding may partly explain the dramatic decrease in partnership formation rates in Southern Europe.

\section{JEL Classification: E21, I29}

Keywords: marriage market, gender roles, household labor

Corresponding author:

José Alberto Molina

Department of Economic Analysis

University of Zaragoza

Gran Vía 2

50005 Zaragoza

Spain

E-mail: jamolina@unizar.es

\footnotetext{
* This paper has greatly benefited from the comments at the Annual Conference of the European Society for Population Economics (2007), the British Household Panel Survey Conference at the University of Essex (2007), the Annual Congress of the European Economic Association (2007), and the Annual Symposium of Economic Analysis at the University of Oviedo (2006). The authors would like to express their thanks for the financial support provided by the Spanish Ministry of Education and Science (Project SEJ2005-06522), and Ramon Areces Foundation.
} 


\section{Introduction}

During the past decade, below replacement fertility in most developed countries has drawn the attention of researchers in a variety of social science disciplines. Special focus has been given to the so called lowest-low fertility countries, i.e. those countries with fertility persisting well below replacement levels (e.g., Kohler, Billari, and Ortega 2002). Among these countries Spain, Italy and Japan are the leading examples with average total fertility rates of 1.2. Below replacement fertility presents new economic challenges for a society, as it changes the age structure of the population and may require structural adaptations with important implications for welfare (e.g., Weil 1999). These factors have become of special concern for lowest-low fertility countries, in which the sharp decline in fertility together with a slow increase in female labor force participation has raised questions about the viability of pay-as-you-go pension systems (e.g., Rindfuss, Guzzo, and Morgan 2003).

Most of the research on lowest-low fertility has focused on the number of children in married households. This approach may be partly justified by the lack of out-of-wedlock fertility and high marriages rates in the past (e.g., Bettio and Villa 1998). However, while the decline in marriage has been followed by an increase in cohabitation and out-of-wedlock fertility in most European countries, this has not occurred in lowest-low fertility countries. ${ }^{1}$ Substantial declines in marriage in lowest-low fertility countries, together with the fact that these countries have not experienced the increase in out-of-wedlock fertility and cohabitation characteristic of other developed countries, call into question previous fertility studies based solely on marital fertility and draw new attention onto household formation decisions as a contributor to fertility phenomena.

The top panel of Table 1 shows cohort evidence from the ECHP that partnership formation rates (either marriage or cohabitation) has changed differently across European countries. Although partnership formation rates are lower for younger cohorts of women in all countries, differences in partnership formation rates across countries start to emerge for cohorts born after 1950. In particular, lowest-low fertility countries such as Italy and Spain have the lowest partnership formation rates for cohorts born after 1950, with 77 and 74 percent of women having ever been in a partnership for the cohort of women born between 1960 and 1970, as opposed

\footnotetext{
${ }^{1}$ See (Retherford, Ogawa, and Matsukura 2001) for a detailed description of the Japanese case and (Rosina and Fabroni 2004) for the Italian case.
} 
to higher fertility countries such as Denmark or the UK, with partnership formation rates of 89 and 85 for the same cohort. ${ }^{2}$ The bottom panel of Table 1 shows completed cohort fertility rates for these cohorts of women. As with partnerships, completed cohort fertility has declined for all countries, but more so for Southern European countries. ${ }^{3}$ In fact, the cross-country correlation between completed cohort fertility and partnership rates has changed from being negative for the oldest cohorts to becoming positive for the younger cohorts. ${ }^{4}$

This paper presents a social norms interpretation to explain differences in partnership formation rates across countries and particularly the dramatic decrease in partnership formation rates in Southern Europe. We argue that more traditional social norms regarding the household division of labor negatively affect a woman's probability of entering a household, which might explain why countries with more traditional social norms may also have lower partnership formation rates. In this context increases in female human capital - by raising the opportunity cost of entering a partnership- had a more negative impact on partnership formation rates in Southern Europe due to the more traditional social norms regarding the household division of labor. Our focus is motivated by time-use studies showing that a substantial amount of non-market work is devoted to home production (e.g., Hersch and Stratton 2002) and the growing evidence that fathers are increasingly involved in childcare (e.g., Goldscheider and Kaufman 1996). In fact, a comparison of high-fertility with low-fertility industrialized countries indicates that men's involvement in household tasks is considerably higher in high-fertility countries. For example, weekly hours devoted to housework by men in Japan is 3.5 versus 13.8 hours by men in the United States (e.g., Juster and Stafford 1991). Similarly, more recent time use studies in Europe reveal that Spanish women devote one more hour to domestic work per day than Swedish women and that only 70 percent of Spanish and Italian men versus 92 percent of Swedish men ever engage in household activities (e.g., Eurostat 2006).

Incorporating social norms into an economic model of household formation contributes to

\footnotetext{
${ }^{2}$ These figures are very similar for women born between 1960 and 1965, who are between 30 and 34 years old in 1994 (the first wave of the ECHP). Thus, although these figures may reflect a delay in partnership formation among Mediterranean countries, the fact that women in this cohort are already between 24 and 34 years old in 1994 and the lack of out-of-wedlock fertility in Southern European countries means that this delay is likely to have a negative effect in fertility. Partnership rates for women born between 1960 and 1965 are both 0.83 in Spain and Italy.

${ }^{3}$ It is precisely this evidence from completed cohort fertility levels that has led demographers to agree that the current lowest-low fertility levels in Southern Europe are not a mere product of a tempo effect or postponement in births. See (Frejka and Calot 2001) for a complete study of cohort reproductive patterns in low-fertility countries.

${ }^{4}$ The correlation for the oldest cohort is -0.26 , whereas for the youngest it is 0.58 . These correlations become less positive (-0.52 and 0.06 respectively) when Ireland is considered.
} 
the recent literature that looks at how social norms (or culture) shape an individual's economic behavior, such as savings decisions (e.g., Carroll and Rhee 1994), fertility and female labor force participation (e.g., Fernández, Fogli, and Olivetti 2006), and living arrangements (e.g., Giuliano 2007). Social norms are to a large extent enforced through non-market interactions and thus difficult to isolate empirically. This literature tries to identify the effect of social norms by looking at the behavior of immigrants in the United States and find that, in most cases, immigrants replicate the behavior of the individuals in their country of origin. This replica of behavior in a neutral environment with the same institutions, policies, and macroeconomic conditions, suggests that social norms in the country of origin play a role in determining an individual's economic behavior. ${ }^{5}$

In the absence of experimental data, this paper provides two different identification strategies of the effect of social norms on an individual's household formation probability. The first identification strategy comes from the time and cross-country variation of the data. In a similar approach to a difference in difference approach, where the treatment is a continuous rather than a discrete variable (i.e., the degree of social norms in a given country), we are able to identify the effect of social norms net of other country-specific and time-varying factors. A second identification strategy relies on the panel structure of the data, which allows for the identification of the effect of social norms net of (permanent) individual heterogeneity in preferences (e.g., Manski 2000).

We first present a simple partnership formation model to illustrate how social norms on the division of household labor may influence a woman's decision to form a household. Social norms are modeled as a constraint on how potential partners divide the household surplus generated through household production once the partnership has been formed. ${ }^{6}$ The model has two predictions. First, social norms regarding the gender division of labor diminish a woman's gains from entering a household. Thus, a woman living in a country with more traditional social

\footnotetext{
${ }^{5}$ Related to this literature is also the study of social or group effects. In the case of household formation models, Loughram (2002) analyzes the effect of male wage inequality on female's marriage probabilities and Drewianka (2003) exploits variations in a two-sided mate matching market to identify the externalities associated with spousal search.

${ }^{6}$ It is beyond the scope of this paper to look at how social norms are formed and maintained over time. Some authors have argued that the inability of potential partners to credibly commit before the household is formed to make transfers of time, rather than transfers of private consumption, constrain potential partners to rely on gender roles when making a decision on how to divide the household surplus. At the root of this argument are the non-observability by third parties of spouse's time devoted to household production and the absence of credible threats for certain household production activities (especially those related to caring activities) (e.g. Folbre and Bittman 2004).
} 
norms has, ceteris paribus, a lower probability of forming a partnership. Second, women with the highest opportunity cost are more constrained by a traditional gender division of labor, so that the negative effect of social norms on a woman's probability of entering a partnership is higher for highly educated women.

The empirical analysis uses seven waves and 13 countries from the European Community Household Panel data (1995-2001 ECHP). The ECHP data is a cross-country data that contains individual (and household) level information on demographic and economic variables. For each country and year we construct the average of the female to male ratio of childcare time as a measure of social norms regarding the household division of labor. The empirical findings support the predictions of the model. After controlling for the time and country variation in the data, as well as for permanent individual heterogeneity and other aggregate variables, the results suggest that more traditional social norms regarding the household division of labor negatively affect a woman's probability of forming a partnership. Furthermore, as predicted by the model, social norms have a greater negative effect for highly educated women. To the extent that female education has increased over the years, and that Southern European countries have more traditional social norms, this latter finding may partly explain the dramatic decrease in partnership formation rates in Southern Europe.

The paper is organized as follows. Section 2 presents a stylized model of partnership formation. Section 3 describes our empirical strategy. Section 4 describes the ECHP data and presents basic summary statistics and Section 5 presents the results. Section 6 presents some robust checks and Section 7 concludes.

\section{A Model of Partnership Formation and Social Norms}

This section presents a stylized equilibrium model of partnership formation that focuses on how the allocation of household labor by potential partners may influence a woman's probability of entering a partnership. Although a partial equilibrium analysis might seem unsatisfactory from a theoretical perspective, it does not invalidate the empirical results, which can be understood as the general equilibrium outcome of changes in social norms and union formation probabilities.

We focus on two specific aspects of the gains of forming a partnership: efficiency gains from specialization in household production and the consumption of market public goods. ${ }^{7}$ Individual

\footnotetext{
${ }^{7}$ Other dimensions of forming a partnership such as risk pooling or consumption smoothing are left out of the
} 
utilities once a partnership (union) has been formed $V_{i}^{u}$ are given by the sum of the utilities obtained from the consumption of a market public good $c^{u}$ and a household produced public good $z^{u}$, and the disutility from the time spent in the production of the household public good $f\left(h_{i}^{u}\right)$. The composite consumption good includes market consumption goods that are jointly consumed by the household $c^{u}$ (such as groceries, housing, child care, etc.) and that can be acquired in the market at a normalized price $p=1$. Similar to Becker's original marriage market model, a woman's decision to form a household takes place when her individual utility within a partnership $V_{i}^{u}$ is equal to or greater than her utility if single $V_{i}^{s}$.

The household produced good $z^{u}$ can be understood without loss of generality as a lower bound for the amount of household production that needs to be done in the household. These are the "commodities" in a Beckerian sense, such as a cleaned house or home-made meals (see Becker 1975). The household produced good $z^{u}$ is consumed jointly by both partners but differs from $c^{u}$ in that it cannot be purchased in the market. Instead, it is produced using both partners' time in household production such that $z^{u}=h_{m}^{u}+h_{f}^{u}$, for $0 \leq h_{i}^{u} \leq 1$ and $i=m, f .{ }^{8}$ Each partner derives disutility $f\left(h_{i}^{u}\right)$ from the time devoted to household production $h_{i}^{u}$, where $f($.$) is an increasing and convex cost function. We can write an individual's utility within the$ household as $V_{i}^{u}=U\left(z^{u}\right)-f\left(h_{i}^{u}\right)+c^{u}$, for $i=m, w$. Appendix A describes one possible household maximization problem that rationalizes the individual utilities presented here. We can write each partner's time devoted to household production $h_{i}^{u}$ as a fraction of the produced output such that $h_{m}^{u}=(1-\alpha) z^{u}$ and $h_{f}^{u}=\alpha z^{u}$ for $0 \leq \alpha \leq 1$, where $\alpha$ is the share of total household labor done by the woman.

Social norms regarding the division of household labor are modeled as a lower bound $\underline{h}_{f}^{u}$ that constrain a woman's housework time to be greater or equal to the value dictated by the existing gender roles in the country she lives in, so that $h_{f}^{u} \geqslant h_{f}^{u}$. More traditional social norms regarding the household division of labor are captured in the model by a higher $h_{f}^{u}$. In other words, the constraint (if binding) effectively prevents potential partners to perfectly contract upon the desired division of household labor once the partnership is formed. The model specification, where the only private goods are the disutility from time devoted to household production, analysis for exposition purposes.

${ }^{8}$ The assumption of perfect substitutability between partners' time in household labor is made for expositional purposes only. The results are robust to more general specifications of the production function, which may include market goods as inputs in the production of the household-produced public good as well as other forms of substitutability between partners' time. 
implies that it is not possible to compensate a woman for having a socially constrained partner.

The predictions of the model are twofold. First, a straight forward application of the envelope theorem implies that household utility is decreasing in $h_{f}^{u}$. It is thus easy to show that a woman's individual utility within the partnership is decreasing in $h_{f}^{u}$ as well. Thus, a woman living in a country with more traditional social norms regarding the household division of labor extracts a lower utility from a partnership and has a lower probability of forming a partnership, everything else being constant, than another woman living in a country with a less traditional division of household labor. This prediction may explain the current cross-country differences in partnership rates on account of the different social norms regarding the household division of labor across countries.

The second prediction of the model is that, given the social constraint imposed by social norms, the utility loss when a partnership is formed is lower the higher the female wage. I.e. those women with the highest opportunity cost have the most to loose when constrained to a traditional division of labor within the household and are the ones less likely to enter a partnership. ${ }^{9}$ To the extent that female education has increased over the years, and that Southern European countries have more traditional social norms, this prediction may partly explain the dramatic decrease in partnership formation rates in Southern Europe.

\section{Empirical Strategy}

In order to explain the current cross-country differences in partnership formation rates on account of the different social norms across countries we first start by estimating a baseline linear probability model of a woman's probability of forming a household as a function of observable individual characteristics and a country's social norms regarding the household division of labor. ${ }^{10}$ The dependent variable in Equation (1) is the probability that a woman has ever been in

\footnotetext{
${ }^{9}$ It is easy to show that the constraint is more likely to bind the higher the female wage. I.e., there is a wage $w_{f}^{u}$ such that if $w_{f} \geqq w_{f}$ the constraint becomes binding. Also, given a binding constraint $h_{f}^{u}$, it is easy to see that the utility a woman gets within the household is lower the higher the woman's wage.

${ }^{10}$ The fact that the data allows the use of individual fixed effects makes the linear probability model particularly attractive with respect to other models such as the conditional logit model. Although the linear probability model might not provide a very good estimate of the partial effects at extreme values of the independent variables, it still produces a consistent and even unbiased estimator of the partial effects on the response probability averaged across the distribution of the independent variable.
} 
a partnership and takes value one if a woman has ever formed a household, and zero otherwise.

$$
p(y=1 \mid x)_{i, t, k}=X_{i, t, k} \beta_{1}+T I_{t, k} \beta_{2}+\varepsilon_{i, k}
$$

where $X_{i, t, k}$ is a vector of individual observable characteristics (education, age, and sex). Social norms regarding the household division of labor in year $t$ and country $k$ are captured by the traditionality index $T I_{t, k}$, where higher values of $T I_{t, k}$ represent more traditional social norms regarding the household division of labor. The error term captures, among other things, the unobserved taste for forming a household and is assumed to follow a normal distribution with variance $\sigma_{k}$, which is independently distributed across countries but correlated within countries $k=1 \ldots 13 .^{11}$ The coefficient of interest is $\beta_{2}$. A negative $\beta_{2}$ means that more traditional social norms regarding the household division of labor are correlated with a lower probability of forming a household, which would explain why countries that hold on average a more traditional division of labor may also have lower partnership formation rates. ${ }^{12}$

One of the potential identification problems of the effect of social norms on a woman's partnership formation probability is that any permanent differences across countries over the sample period or any changes over time might lead to a biased coefficient on social norms if these changes are correlated with a woman's partnership formation probability as well as with social norms regarding the household division of labor. In the absence of experimental data, this paper provides two different identification strategies of the effect of social norms on an individual's household formation probability. The first identification strategy comes from the time and cross-country variation of the data. In a similar approach to a difference in difference approach, where the treatment is a continuous rather than a discrete variable (i.e., the degree of social norms in a given country), we are able to identify the effect of social norms net of other time and country fixed effects. Equation (2) thus estimates the same specification as in Equation (1) controlling for country and year fixed effects, where $I_{t}$ and $I_{k}$ are the country and

\footnotetext{
${ }^{11}$ See Moulton (1990) for the need to consider correlated disturbances when estimating the effects of aggregate variables on micro units.

${ }^{12}$ Choosing a relatively large cell size i.e., the respondent's country minimizes measurement error in my estimates of partnerships-market specific social norms. Given that mobility across countries is relatively small, choosing a large cell size also avoids the self-selection problem that is present in most group studies.
} 
year dummies respectively.

$$
p(y=1 \mid x)_{i, t, k}=X_{i, t, k} \beta_{1}+T I_{t, k} \beta_{2}+I_{t} \beta_{4}+I_{k} \beta_{k, 5}+\varepsilon_{i, k}
$$

A second identification strategy relies on the panel structure of the data, which allows for the identification of the effect of social norms net of (permanent) individual heterogeneity in preferences (e.g., Manski 2000). This is particularly important in this context because there is a reason to believe that social norms and individual preferences regarding the household division of labor might be positively correlated. If this is the case, the traditionality index coefficient would be capturing the effect of individual preferences regarding the household division of labor on a woman's partnership formation probability, rather than the effect of social norms as a constraint, which is the way that it has been characterized here. We thus estimate Equation (2) with individual fixed effects. ${ }^{13}$ Unfortunately the ECHP does not contain information on individual preferences regarding the household division of labor. Thus, although using individual fixed effects allows us to control for individual permanent unobserved heterogeneity that might be correlated to social norms, limitations in the data unable us to control for changing individual heterogeneity, such as changing individual preferences toward de household division of labor, that might be correlated to social norms regarding the household allocation of labor. ${ }^{14}$

We test the second prediction of the model, i.e. that the higher the level of education a woman has, the more negative the effect of social norms regarding the household division of labor on a woman's partnership formation probability, by estimating Equation (3), where the traditionality index is interacted with a woman's education level $E d u_{i, t, k}$.

$$
p(y=1 \mid x)_{i, t, k}=X_{i, t, k} \beta_{1}+T I_{t, k} \beta_{2}+I_{t} \beta_{4}+I_{k} \beta_{k, 5}+T I_{t, k} * E d u_{i, t, k} \beta_{6}+\varepsilon_{i, k}
$$

If the way we have modeled social norms is correct, we would expect the coefficient on the

\footnotetext{
13 One might argue that individual's preferences are to some extent the result of social norms. In this case the traditionality index coefficient reported in the fixed effects specification would be a lower bound of the total effect of social norms.

${ }^{14}$ Hamermesh (2004) offers an interesting discussion of what economists can learn from the use of subjective outcomes as inputs to explain economic behavior. See Sevilla (2007) for an example of how to use individual reported attitudes to isolate the effect of social norms on an individual's partnership formation probability.
} 
interaction $\beta_{6}$ to be negative. Thus, to the extent that female education has increased over the years, and that Southern European countries have more traditional social norms, this result may partly explain the dramatic decrease in partnership formation rates in Southern Europe.

\section{The European Community Household Panel Data}

The data comes from the European Community Household Panel (ECHP). This survey is a standardized multi-purpose annual panel data survey spanning from 1994 to 2001 over 15 countries. The ECHP collects information on basic demographic and socio-economic variables such as labor force participation behavior, income, health, education and training, housing, poverty and social exclusion, and some other social indicators about life conditions of households and individuals. ${ }^{15}$ The cross-country nature of the data, its panel structure, and the wealth of information collected in the ECHP make it a perfect candidate for cross-country comparisons across Europe. Particularly important for our analysis is the information regarding the allocation of time to childcare within the household.

\subsection{Sample and summary statistics}

We use a sample of women between 30 and 45 years of age in from 7 of the 8 available waves in the ECHP. We restrict the sample to be within this age range because we are interested in the fertility implications of partnership decisions. Our main results follow when we expand the sample to younger and older women (see Section 6). We drop observations for 1994 as this year does not contain information on the household allocation of childcare time. As is common when using the ECHP we also exclude from the main analysis observations from Sweden (which is not a panel data set) and Luxembourg (because of the small sample size). Thus, we restrict the analysis to women living in the following countries: Austria, Belgium, Denmark, Finland, France, Germany, Greece, Ireland, Italy, Portugal, Spain, The Netherlands and The United Kingdom.

Social norms regarding the household division of labor are captured by the country's tradi-

\footnotetext{
${ }^{15}$ See Peracchi (2002) for a detailed description of the ECHP.
} 
tionality index $T I_{t, k}$, for each year $t$ and country $k$. This index is constructed as:

$$
T I_{t, k}=\left[\sum_{t, k} h w_{i, t, k}-h m_{i, t, k} / h w_{i, t, k}+h m_{i, t, k}\right] x 100
$$

where $h m_{i, t, k}$ denotes the weekly hours devoted to childcare by the man, and $h w_{i, t, k}$ denotes the weekly hours devoted to childcare by the woman, in partnership $i$, year $t$ and country $k .{ }^{16}$. Thus, higher values of this index indicate more traditional social norms regarding the household division of labor. Column 1 in Table 2 shows the average value of the traditionality index in each country for the relevant sample. Countries are ranked from less to more traditional, with a higher value of the index meaning that on average individuals in that particular country hold a more traditional division of labor. Among the most egalitarian countries are Denmark and The Netherlands, whereas Spain and Italy are among the countries with more traditional division of labor.

The dependent variable is whether a woman has ever been in a partnership. A woman is considered to have ever been in a partnership if she is either currently married or has ever been married, or if the respondent is currently living with a partner in a cohabiting union. The crosscountry relationship between the traditionality index and partnership rates is negative (with a value of -0.0036). More egalitarian countries such as Denmark and The Netherlands also seem to have a higher proportion of women in partnerships than do other less egalitarian countries such as Spain or Italy.

Female education has generally been used in the literature as a measure of market human capital and thus as potential female outside opportunities to marriage. We define a dummy for each of the three levels of education in the ECHP. ${ }^{17}$ Columns 3, 4, and 5 in Table 2 show the proportion of women that have low, medium and high education levels respectively. These summary statistics show important cross-country differences in female educational attainment. The countries with highest proportion of low educated women in the sample are Portugal (78.95) and Spain (58.84) while the lowest proportion of low educated women correspond to Finland

\footnotetext{
${ }^{16}$ To construct this index we use information on childcare time from those couples where at least one member reports to do some childcare

${ }^{17}$ These dummies are constructed using the the answers to the question "Highest level of general or higher education completed". The answers to these questions take three values that we code as high education level [Recognized third level education (ISCED 5-7)], medium education level [Second stage of secondary level education (ISCED 3)], and low education level [Less than second stage of secondary education (ISCED 0-2)].
} 
(14.67) and Germany (15.33). The highest proportion of high educated women correspond to Finland (48.25) and the Denmark (47.88) while the lowest rates correspond to Portugal (8.92) and Austria (9.35). The cross-country relationship between the traditionality index and each of the female education levels is 0.18 for the low educated, 0.06 for the medium educated, and -0.15 for the high education level. These results show that controlling for education level in our analysis is important, as more egalitarian countries such as Denmark and Finland also seem to have a lower proportion of low educated women than do other less egalitarian countries such as Spain or Italy.

Although informative, it is difficult to make any causal inferences on the relationship between social norms toward the household division of labor and household formation probabilities from these raw cross-country averages. Section 5 takes into account country, year, and individual heterogeneity to shed some light onto the effect of these variables on a woman's household formation probability.

\section{Household Division of Labor and a Woman's Partnership Formation Probability}

Column 1 in Table 3 shows the results from estimating a pooled Ordinary Least Squares regression as specified in Equation 1 of a woman's probability of entering a partnership. The coefficient on the traditionality index is negative and significant, which suggests that the relationship observed at the cross-country level in Table 2 also exists at the individual level. Its size is 7.4, meaning that a an increase of 100 in the traditionality index is associated with a 7.4 percentage points lower probability of forming a household. Thus, a woman living in Denmark, with the highest traditionality index of 29.90 , has a probability 3.7 percentage points higher of entering a partnership than a woman living in Greece, with the lowest traditionality index of 79.01 .

As mentioned in Section 3, the egalitarian index coefficient presented in Column 1 of Table 3 cannot be interpreted causally. The specifications in Columns 2 and 3 control separately for survey-year and country fixed effects that might be correlated with a country's traditionality index by adding year $I_{t}$ and country dummies $I_{k}$ in the right hand side of Equation (1). Introducing a survey-year fixed effect in Equation (1) does not significantly change the traditionality 
index coefficient. Column 3 of Table 3 shows however that the coefficient on the traditionality index becomes positive and significant when adding country dummies to the baseline regression specification in Equation (1). This specification, however, does not have time variation in it. To have a complete picture we need to look at Column 4.

Column 4 in Table 3 is the preferred specification so far and presents the results from estimating Equation (2), which includes both year and country dummies to account for both permanent differences across countries over the survey period, and changing factors over time in all countries. The size of the traditionality index coefficient is much lower than in the previous specifications, and its magnitude is reduced by a factor of 10 with respect to Specification (1). The coefficient is also no longer statistically significant. This decrease in the size of the coefficient suggests that omitting year and country fixed effects results in an overestimation of the effect of social norms on an individual's household formation probability. In particular, a 100 increase in the traditionality index leads to a 0.7 percentage points decrease in the probability of entering a household or a .37 percentage points difference between a woman living in Denmark and a woman living in Greece.

Finally, Column 5 in Table 3 estimates Equation 1 using a fixed effects estimator that controls for individual permanent unobserved heterogeneity. The coefficient on the traditionality index is .19 and is not statistically significant. Thus, not controlling for individual unobserved heterogeneity leads to an overestimation of the effect of social norms regarding the household division of labor on a woman's probability of forming a household and that, in fact, individual preferences and social norms regarding the household division of labor are positively correlated.

The above results may suggest that social norms regarding the household division of labor have not a significant effect on a woman's probability of forming a partnership. However, one implication of the model presented in Section 2 is that social norms differentially affect a woman's probability of forming a household depending on her level of education. In particular, social norms regarding the division of household labor are more likely to reduce a woman's probability of entering a partnership the higher the woman's education level. To the extent that there is indeed a differential effect of social norms on a woman's probability of forming a partnership by education levels, the estimates presented in Table 3 may hide the real relationship between social norms and a woman's household formation probability because they are averages across education levels. 
We explore whether social norms have a different effect on a woman's probability of entering a partnership by education level in Table 4 . Table 4 presents the same specifications as in Table 3 , where we interact the traditionality index with a woman's level of education to see whether there is a differential effect of social norms by education levels. The prediction in the model is strongly confirmed. Column (5) in Table 4 shows that for women with high education level the coefficient is negative and highly statistically significant. Its magnitude increases to 2.5 with respect to the specification presented in Column 5 of Table 3. The coefficient on the traditionality index is very similar for women with low and medium levels of education. Although positive and significant, this coefficient is much lower than for women with high education levels (0.4 percentage points).

The coefficients on the rest of the variables are as expected. The relationship between age and the probability of having ever been in a partnership is an inverted U-shape and does not significantly change across specifications. One additional year of age increases the probability to have ever been in a partnership by 6.92 percentage points with a peak at 33 years of age, when the probability of having ever been in a partnership starts to decrease with each year of age. The level of education is negatively associated with the probability of having ever been in a partnership in most specifications, although the coefficients are small and become positive in the fixed effects specifications (Column 5). These results suggest that part of the observed association between level of education and the probability of having ever been in a partnership comes from individual unobserved heterogeneity and highlights the need to account for these unobserved factors.

\section{Robust Checks}

\subsection{Country varying factors}

The estimates presented in Table 2 yield an unbiased estimate of the social norms coefficient $\beta_{2}$ so long as the country fixed effects do not vary over the survey period and the year fixed effect does not vary across countries. There might be, however, changing factors at the country level that are correlated with both, an individual's probability of entering a household and a country's social norms toward the household division of labor. These country-year effects are thus not controlled for by either the year or the country fixed effects, and omitting them might 
bias the traditionality index coefficient $\beta_{2}$. Among these country-specific variables are family policies, and labour market and marriage market conditions. Introducing these country-year variables in the analysis may allow us to differentiate whether the traditionality index coefficient captures the effect of social norms toward the division of household labor on an individual's household formation probability, or whether this coefficient is just capturing the effect of these country-specific variables.

As is common in the marriage market literature, we control for the Sex Ratio in each country and year defined as the number of women per 100 men, to capture any effect of the conditions of the household market on an individual's household formation probability. ${ }^{18}$ The underlying idea is that if the Sex Ratio is lower, women are better valued in the marriage market and they do not need to compensate their partners for their undesired characteristics, so that they do not need to devote so much time to Work-In-Marriage (e.g., Grossbard-Sechtman 1984). As a result, the Sex Ratio would have a positive correlation with a woman's probability of forming a household. To the extent that the Sex Ratio in a country is correlated with social norms regarding the household division of labor, we might expect the traditionality index coefficient to be biased and the direction of this bias will depend on the sign of this correlation.

We also include the Female Activity Rate, and the percentage spent in family policies out of total public expenditure. These variables should control for female labor market and public support conditions that might affect the costs and benefits a woman faces when forming a household. For example, there is some evidence that welfare benefits have a positive effect on the prevalence of single motherhood and thus a negative effect on a woman's probability of forming a household (e.g., Gonzalez 2007). As before, to the extent that these variables are correlated with social norms regarding the household division of labor, we might expect the traditionality index coefficient to be biased.

Table 5 shows the summary statistics of these aggregate variables by country. As in Table 2 countries in Table 5 are ordered from least to most traditional according to the traditionality index constructed in Section 4. Column 1 shows the Sex Ratio, which varies from 101.33 in Ireland to 107.41 in Portugal and has a positive correlation with the egalitarian index of 0.1481 , meaning that more egalitarian countries have a lower Sex Ratio than less egalitarian countries.

\footnotetext{
${ }^{18}$ Grossbard and Amuedo-Dorantes (2007) analyze the effect of sex ratios on married women's labor force participation. In their model more favorable sex ratios for women increase the gains from marriage and thus make it less likely for any woman to participate in the labor force.
} 
Column 2 in Table 5 shows the percentage of public expenditure spent in family policies, which varies from 13.19 and 12.80 in Ireland and Denmark to 2.39 and 3.61 in Spain and Italy. The cross-country correlation between the percentage spent on family policies out of total public expenditure and the traditionality index is -0.4072 . Column 3 in Table 5 shows the Female Activity Rate, which varies from 84.64 in Finland to 59.13 in Italy. The correlation between the egalitarian index and the Female Activity Rate is -0.5207. These last two negative correlations indicate that countries with less traditional social norms regarding the household division of labor also have a higher percentage of public expenditure spent in family policies as well as a higher Female Activity Rate.

To explore the potential bias in the traditionality index coefficient from omitting these country-year variables, Columns 2 to 4 in Table 6 present the results from estimating Equation (3) by first introducing these variables one by one. Results are compared to those in Column 1, which presents the results from estimating the effect of the traditionality index by education levels controlling for year and country dummies and permanent unobserved heterogeneity as in Column 5 of Table 4. The coefficient on a country's Sex Ratio is 0.005, which indicates that a one standard deviation increase, which corresponds to an increase of 1.87 in the Sex Ratio, is associated with a 0.93 percentage points increase in a woman's probability of forming a household. The coefficient on the Female Labor Force Participation is negative and significant, although the size of this coefficient is very small. This negative coefficient might suggest that women living in countries where Female Labor Force Participation is high have a lower probability of forming a household. This result is somewhat contradictory to the positive cross-country correlation between fertility and female participation found since the mid eighties (e.g., Adsera 2004) and some evidence that women living in countries with a higher female participation experience, have on average, faster transitions to a first birth (e.g., Adsera 2005). The coefficient on the percentage spent in family policies is positive although its magnitude is very small and is not significant.

All in all, including these variables as controls do not seem to change the size or significance of the egalitarian index coefficient, which remains at values very similar to the baseline specification presented in Column 1 of Table 6. For completeness Column 5 in Table 6 presents the results from estimating Equation (1) controlling for the two country-level variables whose coefficients are significant, the Sex Ratio and the Female Labor Force Participation in a country. As expected 
from the previous results, the egalitarian index coefficient remains unchanged.

\subsection{Other Robust Checks}

Table 7 shows some robust checks of the effect of social norms on a woman's probability of forming a household. The columns in Table 7 show the traditionality index coefficient from estimating the same specifications as in Table 4. The top panel of Table 7 use a time trend rather than year dummies as regressors. The second and third panels in Table 7 use a sample of women between 30 and 50, and between 25 and 50 years of age respectively. The fourth panel of table 7 uses a traditionality index constructed using a random sample of couples rather than all couples with children for each year and country to avoid endogeneity problems. To do this we randomly select seventy percent of all the couples where at least one of the members reports to devote time to childcare activities to calculate the traditionality index. Finally, the bottom panel of table 7 introduces self-reported health and labor status variables as controls. Results in all the above specifications are very similar to the estimates shown in the main specification presented in Table 4.

\section{Conclusion}

The study of below-replacement fertility that is characteristic of industrialized countries has traditionally overlooked household formation processes. However, cross-country differences in household formation rates are significant. Both declines in marriage rates and increases in cohabitation rates have followed very different trends across the developed world. In particular, the so-called lowest-low fertility countries, like Italy, Japan, and Spain, have experienced a decline in marriage rates that have not been accompanied by increases in cohabitation (and out-ofwedlock fertility) rates characteristic of other developed countries. It thus becomes increasingly important to look at household formation processes for the study of fertility.

This paper complements conventional economic analysis and presents a social norms interpretation to explain cross-country differences in partnership formation rates, and particularly the dramatic decrease in partnership formation rates in Southern Europe. We argue that increases in female human capital- by raising the opportunity cost of entering a partnership - had a differential impact on partnership formation rates in Northern and Southern Europe due to the different social norms regarding the household division of labor. 
Social norms are modeled as a constraint on the allocation of household labor, which may diminish the gains to enter a partnership. Thus, a woman living in a country with a more traditional division of household labor has, ceteris paribus, a lower probability of forming a partnership. Furthermore, the social constraint is more likely to bind for highly educated women. To the extent that female education has increased over the years, and that Southern European countries have more traditional social norms, this latter prediction may partly explain the dramatic decrease in partnership formation rates in Southern Europe.

The empirical findings support the predictions of the model. After controlling for the time and country variation in the data, as well as for permanent individual heterogeneity and other aggregate variables at the country level, the results suggest that more traditional social norms regarding the household division of labor negatively affect a woman's probability of forming a partnership and that the effect of social norms have is specially negative for highly educated women.

It has been beyond the scope of this paper to look at how social norms are formed and maintained over time. Understanding these processes, however, might provide the theoretical and empirical foundations for designing work and family policies (for example, policies geared toward solving imperfect commitment mechanisms within the household that may constrain the allocation of household time to what is prescribed by social norms). We leave this issue for further research. 


\section{References}

Adsera, A. (2004): "Changing Fertility Rates in Developed Countries. The impact of Labour Market Institutions," Journal of Population Economics, 17, 17-43.

(2005): "Where Are the Babies? Labor Market Conditions and Fertility in Europe," IZA Discussion Paper n 1576.

Becker, G. (1975): "Theory of the Allocation of Time," Economics Journal, 75, 493-517.

Bettio, F., And P. Villa (1998): "A Mediterranean Perspective on the Breakdown of the Relationship between Participation and Fertility," Cambridge Journal of Economics, 22, 13771.

Carroll, C. D., and B.-K. Rhee (1994): "Are There Cultural Effects on Saving? Some Cross-Sectional Evidence," Quarterly Journal of Economics, 109, 685-699.

Council of Europe (2001): "Recent Demographic Developments in Europe," Council of Europe Press.

DrewiankA, S. (2003): "Estimating Social Effects in Matching Markets: Externalities in Spousal Search," The Review of Economics and Statistics, 85, 409-423.

Eurostat (2006): How is the time of women and men distributed in Europe. Office for Official Publications of the European Communities, Luxembourg, Brussels.

\section{(2007): Statistics in Focus. Luxembourg.}

Fernández, R., A. Fogli, and C. Olivetti (2006): "Fertility: The Role of Culture and Family Experience," Journal of the European Economic Association, 4, 552-561.

Folbre, N., and M. Bittman (2004): Family Time: The Social Organization of Care. Routledge, New York, NY.

Frejka, T., and G. CALOt (2001): "Cohort reproductive patterns in low-fertility countries," Population and Development Review, 27, 103-132.

Giuliano, P. (2007): "Living Arrangements in Western Europe: Does Cultural Origin Matter?," Journal of the European Economic Association, Forthcoming.

Goldscheider, F., And G. Kaufman (1996): "Fertility and Commitment: Bringing Men Back In," Population and Development Review, 22, 87-99.

Gonzalez, L. (2007): "The effect of Benefits on Single Motherhood in Europe," Labour Economics, 14, 393-412.

Grossbard, S., and C. Amuedo-Dorantes (2007): "Marriage Markets and and Women's Labor Force Participation," Review of Economics of the Household, Forthcoming.

Grossbard-Sechtman, A. (1984): "A Theory of Allocation of Time in Markets for Labour and Marriage," The Economic Journal, 94, 863-882.

Hamermesh, D. S. (2004): "Subjective Outcomes in Economics," NBER WP 10361. 
Hersch, J., And L. S. Stratton (2002): "Housework and Wages," Journal of Human Resources, 37, 217-229.

Juster, T., And F. Stafford (1991): "The Allocation of Time: Empirical Findings, Behavioral Models, and Problems of Measurement," Journal of Economic Literature, 29, 471-522.

Kohler, H. P., F. C. Billari, and J. A. Ortega (2002): "The Emergence of Lowest Low Fertility in Europe during the 1990's," Population and Development Review, 28, 641-680.

Loughram, D. S. (2002): "The Effect of Male Wage Inequality on Female Age at First Marriage," The Review of Economcs and Statistics, 84, 237-250.

Lundberg, S., and R. A. Pollak (1996): "Bargaining and Distribution in Marriage," The Journal of Economic Perspectives, 10, 139-158.

Manski, C. F. (2000): "Economic Analysis of Social Interactions," Journal of Economic Perspectives, 14, 115-136.

Moulton, B. R. (1990): "An Illustration of the Pitfall in Estimating the Effects of Aggregate Units on Micro Units," Review of Economics and Statistics, 72, 334-338.

Peracchi, F. (2002): "The European Community Household Panel: A review," Empirical Economics, 27, 63-90.

Retherford, R., N. Ogawa, and R. Matsukura (2001): "Late Marriage and Less Marriage in Japan," Population and Development Review, 27, 65-102.

Rindfuss, R., K. B. Guzzo, and S. P. Morgan (2003): "The changing institutional context of low fertility," Population Research and Policy Review, 22, 411-438.

Rosina, A., And A. FABroni (2004): "Is marriage loosing its centrality in Italy?," Demographic Research, 11.

Sevilla, A. (2007): "Division of Household Labor and Cross-Country Differences in Household Formation Rates," Oxford University Department of Economics Discussion Paper N 325.

WeIL, D. (1999): "Population Growth, Dependency, and Consumption: Why Has Fertility Fallen below Replacement in Industrial Nations, and Will It Last?," American Economic Review, 89, 251-255, Papers and Proceedings of the One Hundred Eleventh Annual Meeting of the American Economic Association. 


\section{Appendix A: Household Maximization Problem}

The household's utility is defined as the sum of individual utilities such that $V^{u}=U\left(z^{u}\right)-$ $\gamma_{m} f\left(h_{m}^{u}\right)-\gamma_{f} f\left(h_{f}^{u}\right)+c^{u}$. The household's maximization problem is given by:

$$
\begin{aligned}
& \max _{c_{i}, h_{i}} U\left(z^{u}\right)-\gamma_{m} f\left(h_{m}^{u}\right)-\gamma_{f} f\left(h_{f}^{u}\right)+c^{u} \\
& s t . \\
z^{u} \geq & h_{m}^{u}+h_{f}^{u} \\
c^{u}= & \sum_{i}\left(1-h_{i}^{u}\right) w_{i} \\
0 \geq & h_{i}^{u} \leq 1 \text { for } i=f, m \\
c^{u} \geq & 0 \text { for } \mathrm{i}=\mathrm{f}, \mathrm{m}
\end{aligned}
$$

where $w_{m}$ and $w_{f}$ are a man's and woman's wages respectively. It is easy to see that at the optimum the household consumes all the joint disposable income and produces the needed amount of household production. The amount of time that each partner devotes to household production $h_{i}^{u}$ is given by the first order conditions $h_{i}^{u}:-w_{i}+U^{\prime}\left(z^{u}\right)-f^{\prime}\left(h_{i}^{u}\right)=0$, for $i=m, f$. As usual, if $w_{m}$ is greater or equal than $w_{f}$, the male partner will devote less time to household production for a sufficiently low $\gamma_{m}$. Under the assumption of interior solution, the second order conditions $h_{i}^{u}: 2 U^{\prime \prime}\left(c^{u}\right) w_{i}^{2}+2 U^{\prime \prime}\left(z^{u}\right)-f^{\prime \prime}\left(h_{i}^{u}\right) \leq 0$ are satisfied for $i=m, f$.

For expositional purposes we assume that the only private goods are essentially the disutility of time devoted to household production and subtract from examining the internal distribution of consumption within the household. We are thus implicitly assuming a unitary model of household decision-making. The literature has vastly recognized that households behave in a much more complex way (e.g., Lundberg and Pollak 1996). However, if we take the traditional assumption that the household maximizes in a two-step process, where hours of household labor and the amount of the commodities to be produced are determined independent of the sharing rule, then the basic predictions of the model do not change under a more complex household decision-making process.

The decision for a single individual is straightforward. She maximizes his or her utility $V_{i}^{s}=U\left(z^{s}\right)-f\left(h_{i}^{s}\right)+c_{i}^{s}$ for $i=m, f$ with respect to the market good $c_{i}^{s}$, the produced good $z^{s}$, and the amount of time spent in household production $h_{i}^{s}$. Without loss of generality we assume that the amount of household work that needs to be done in the single household is less than that in the married household so that $z^{s}<z^{u}$. The solution to this problem is straightforward and given by $h_{i}^{* s}=z^{* s}$ and $c_{i}^{* s}=\left(1-z^{* s} w_{i}\right)$. 
Table 1: Partnership and Completed Cohort Fertility Rates across Europe ${ }^{1,2}$

\begin{tabular}{lcccc}
\hline \hline & $1930-1940$ & $1940-1950$ & $1950-1960$ & $1960-1970$ \\
\hline Partnership Formation Rates & & & & \\
\hline Austria & 0.97 & 0.96 & 0.92 & 0.83 \\
Belgium & 0.95 & 0.97 & 0.95 & 0.90 \\
Denmark & 0.98 & 0.96 & 0.96 & 0.89 \\
Finland & 0.92 & 0.92 & 0.93 & 0.83 \\
France & 0.95 & 0.95 & 0.92 & 0.84 \\
Germany & 0.95 & 0.96 & 0.93 & 0.81 \\
Greece & 0.96 & 0.96 & 0.96 & 0.85 \\
Ireland & 0.92 & 0.94 & 0.9 & 0.75 \\
Italy & 0.94 & 0.93 & 0.94 & 0.76 \\
Netherlands & 0.95 & 0.97 & 0.93 & 0.85 \\
Portugal & 0.93 & 0.96 & 0.93 & 0.87 \\
Spain & 0.95 & 0.94 & 0.91 & 0.74 \\
United Kingdom & 0.95 & 0.96 & 0.93 & 0.85 \\
\hline European Countries & 0.95 & 0.95 & 0.93 & 0.83 \\
\hline \hline Completed Cohort Fertility Rates & & & & \\
\hline Austria & 2.30 & 1.98 & 1.75 & 1.64 \\
Belgium & 2.24 & 1.97 & 1.84 & 1.82 \\
Denmark & 2.33 & 2.08 & 1.88 & 1.92 \\
Finland & 2.26 & 1.92 & 1.92 & 1.92 \\
France & 2.54 & 2.25 & 2.12 & 2.06 \\
Germany & 2.10 & 1.83 & 1.67 & 1.56 \\
Greece & 2.10 & 2.04 & 1.96 & 1.80 \\
Italy & 3.38 & 3.18 & 2.61 & 2.29 \\
Netherlands & 2.24 & 2.03 & 1.75 & 1.58 \\
Portugal & 2.46 & 2.03 & 1.87 & 1.80 \\
Spain & 2.83 & 2.39 & 1.98 & 1.82 \\
United Kingdom & 2.61 & 2.37 & 1.88 & 1.67 \\
\hline European Countries & - & - & 1.99 & 1.91 \\
\hline \hline
\end{tabular}

Notes: ${ }^{1}$ Partnership Formation Rates are calculated by the authors from the ECHP as the proportion of women who report being currently in a partnership or having ever been in a partnership. Results do not significantly change when only the proportion of women who report to currently being in a partnership (although partnership rates are significantly lower for older cohorts). ${ }^{2}$ Completed Fertility Rates taken from the Council of Europe (2001) and are defined as the average number of children born to a cohort of women up to the end of their childbearing age, where age-specific fertility rates are summed up from the cohorts beginning of exposure to risk (at age 15) until the age when all members of the cohort have reached the end of the reproductive period (at age 49 ). 


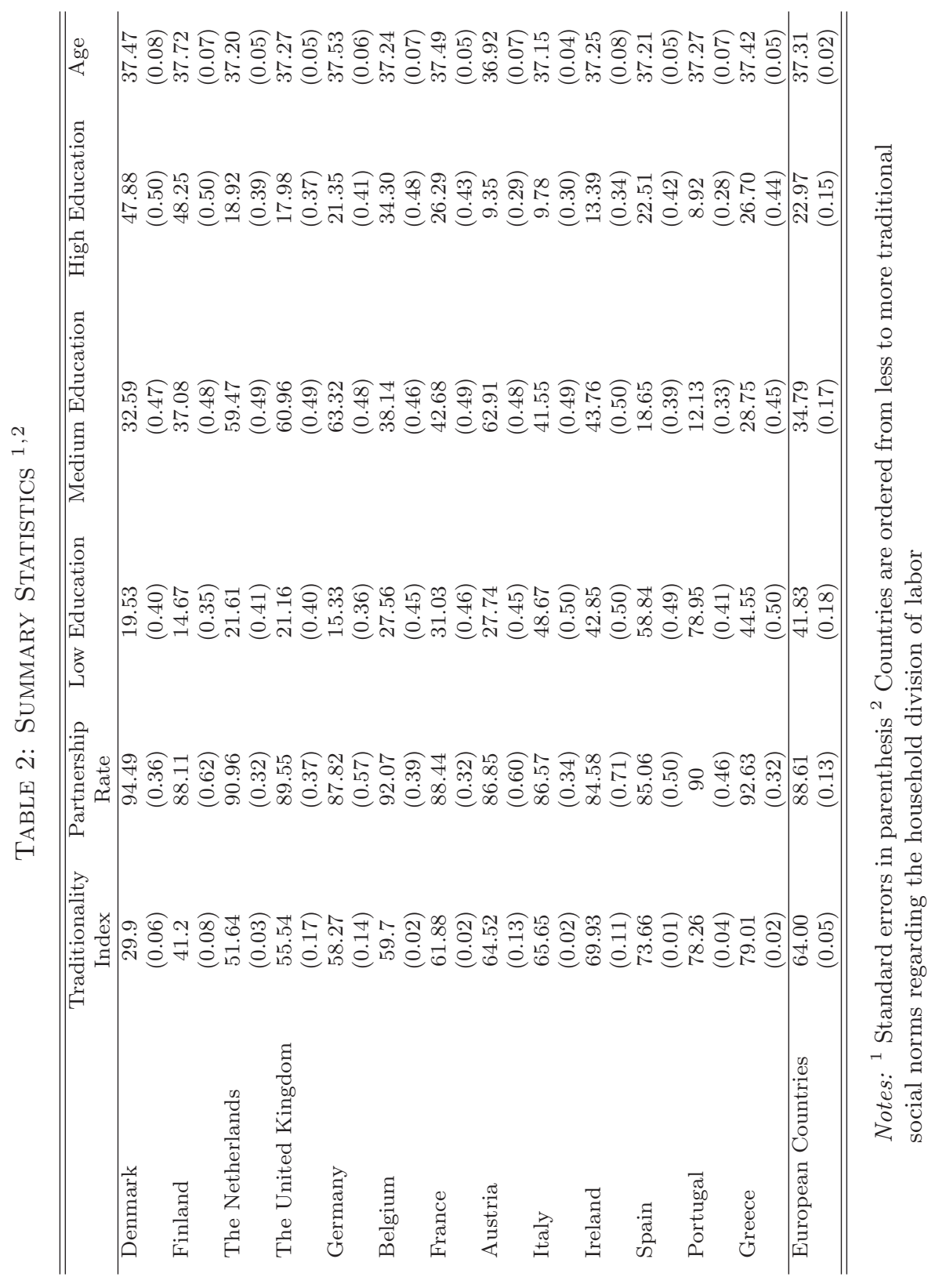


Table 3: The Effect of Social Norms Regarding the Household Division of Labor on the Probability of Having ever Been in a Partnership ${ }^{1,2,3}$

\begin{tabular}{lccccc}
\hline \hline & $(1)$ & $(2)$ & $(3)$ & $(4)$ & $(5)$ \\
\hline traditionality index & $-7.4445^{* * *}$ & $-8.4653^{* * *}$ & $8.3759^{* * *}$ & -0.7080 & -0.1951 \\
& $(0.9643)$ & $(0.9827)$ & $(3.1784)$ & $(3.5039)$ & $(0.7532)$ \\
age & $0.0652^{* * *}$ & $0.0652^{* * *}$ & $0.0656^{* * *}$ & $0.0655^{* * *}$ & $0.0694^{* * *}$ \\
& $(0.0054)$ & $(0.0053)$ & $(0.0053)$ & $(0.0053)$ & $(0.0132)$ \\
age2 & $-0.0760^{* * *}$ & $-0.0727^{* * *}$ & $-0.0762^{* * *}$ & $-0.0734^{* * *}$ & $-0.0217^{* * *}$ \\
& $(0.0070)$ & $(0.0069)$ & $(0.0069)$ & $(0.0069)$ & $(0.0025)$ \\
medium education level & $-0.0114^{* * *}$ & $-0.0135^{* * *}$ & $-0.0112^{* * *}$ & $-0.0122^{* * *}$ & 0.0015 \\
& $(0.0028)$ & $(0.0028)$ & $(0.0029)$ & $(0.0029)$ & $(0.0014)$ \\
high education level & $-0.0558^{* * *}$ & $-0.0568^{* * *}$ & $-0.0611^{* * *}$ & $-0.0613^{* * *}$ & 0.0030 \\
& $(0.0036)$ & $(0.0036)$ & $(0.0036)$ & $(0.0036)$ & $(0.0024)$ \\
_cons & $-0.5265^{* * *}$ & $-0.5532^{* * *}$ & $-0.6064^{* * *}$ & $-0.5947^{* * *}$ & $-1.5433^{* * *}$ \\
& $(0.1006)$ & $(0.1007)$ & $(0.1014)$ & $(0.1012)$ & $(0.5313)$ \\
Cohort dummies & Yes & Yes & Yes & Yes & Yes \\
Country dummies & No & No & Yes & Yes & Yes \\
Year dummies & No & Yes & No & Yes & Yes \\
\hline R sq. & 0.031 & 0.033 & 0.038 & 0.039 & 0.007 \\
N & 120947 & 120947 & 120947 & 120947 & 121084 \\
\hline \hline
\end{tabular}

Notes: ${ }^{1}$ The reported coefficients come from estimating a linear probability model on the probability to have ever been in a partnership ${ }^{2}$ Standard errors in parenthesis $3 * * *$ Significant at the $1 \%$ level $* *$ Significant at the $5 \%$ level *Significant at the $10 \%$ level

Table 4: The Effect of Social Norms Regarding the Household Division of Labor on the Probability of Having ever Been in a Partnership by Education Level ${ }^{1,2,3}$

\begin{tabular}{|c|c|c|c|c|c|}
\hline & $(1)$ & $(2)$ & $(3)$ & $(4)$ & $(5)$ \\
\hline traditionality index & $\begin{array}{c}-16.1707^{* * *} \\
(1.4096)\end{array}$ & $\begin{array}{c}-17.2545^{* * *} \\
(1.4244)\end{array}$ & $\begin{array}{l}-1.5418 \\
(3.3255)\end{array}$ & $\begin{array}{c}-10.8383^{* * *} \\
(3.6580)\end{array}$ & $\begin{array}{c}-2.5498^{* * *} \\
(0.8841)\end{array}$ \\
\hline traditionality index $*$ low education level & $\begin{array}{c}11.8774^{* * *} \\
(1.2635)\end{array}$ & $\begin{array}{c}12.0303^{* * *} \\
(1.2630)\end{array}$ & $\begin{array}{c}12.3330^{* * *} \\
(1.2854)\end{array}$ & $\begin{array}{c}12.4017^{* * *} \\
(1.2853)\end{array}$ & $\begin{array}{c}2.9916^{* * *} \\
(0.6007)\end{array}$ \\
\hline traditionality index $*$ medium education level & $\begin{array}{c}11.5110^{* * *} \\
(1.5549)\end{array}$ & $\begin{array}{c}11.5157^{* * *} \\
(1.5546)\end{array}$ & $\begin{array}{c}12.3713^{* * *} \\
(1.5460)\end{array}$ & $\begin{array}{c}12.5238^{* * *} \\
(1.5470)\end{array}$ & $\begin{array}{c}2.9532^{* * * *} \\
(0.5481)\end{array}$ \\
\hline age & $\begin{array}{c}0.0647^{* * * *} \\
(0.0054)\end{array}$ & $\begin{array}{c}0.0646^{* * * *} \\
(0.0053)\end{array}$ & $\begin{array}{c}0.0650^{* * *} \\
(0.0053)\end{array}$ & $\begin{array}{c}0.0649^{* * * *} \\
(0.0053)\end{array}$ & $\begin{array}{c}0.0692^{* * * *} \\
(0.0132)\end{array}$ \\
\hline age 2 & $\begin{array}{c}-0.0754^{* * *} \\
(0.0070)\end{array}$ & $\begin{array}{c}-0.0721^{* * *} \\
(0.0069)\end{array}$ & $\begin{array}{c}-0.0755^{* * *} \\
(0.0069)\end{array}$ & $\begin{array}{c}-0.0727^{* * *} \\
(0.0069)\end{array}$ & $\begin{array}{c}-0.0216^{* * * *} \\
(0.0025)\end{array}$ \\
\hline medium education level & $\begin{array}{l}-0.0086 \\
(0.0091)\end{array}$ & $\begin{array}{l}-0.0099 \\
(0.0091)\end{array}$ & $\begin{array}{l}-0.0107 \\
(0.0093)\end{array}$ & $\begin{array}{l}-0.0122 \\
(0.0093)\end{array}$ & $\begin{array}{c}0.0012 \\
(0.0031)\end{array}$ \\
\hline high education level & $\begin{array}{c}0.0086 \\
(0.0071)\end{array}$ & $\begin{array}{c}0.0084 \\
(0.0071)\end{array}$ & $\begin{array}{c}0.0054 \\
(0.0073)\end{array}$ & $\begin{array}{c}0.0056 \\
(0.0073)\end{array}$ & $\begin{array}{c}0.0156^{* * * *} \\
(0.0038)\end{array}$ \\
\hline _cons & $\begin{array}{c}-0.5322^{* * *} \\
(0.1008)\end{array}$ & $\begin{array}{c}-0.5589 * * * \\
(0.1009)\end{array}$ & $\begin{array}{c}-0.6110 * * * \\
(0.1016)\end{array}$ & $\begin{array}{c}-0.5983^{* * *} \\
(0.1014)\end{array}$ & $\begin{array}{c}-1.5389^{* * * *} \\
(0.5304)\end{array}$ \\
\hline Cohort dummies & Yes & Yes & Yes & Yes & Yes \\
\hline Country dummies & No & No & Yes & Yes & Yes \\
\hline Year dummies & No & Yes & No & Yes & Yes \\
\hline $\mathrm{R}$ sq. & 0.033 & 0.035 & 0.040 & 0.041 & 0.008 \\
\hline $\mathrm{N}$ & 120947 & 120947 & 120947 & 120947 & 121084 \\
\hline
\end{tabular}

Notes: ${ }^{1}$ The reported coefficients come from estimating a linear probability model on the probability to have ever been in a partnership ${ }^{2}$ Standard errors in parenthesis $3 * * *$ Significant at the $1 \%$ level **Significant at the $5 \%$ level $*$ Significant at the $10 \%$ level 
Table 5: Summary Statistics ${ }^{1,2,3}$

\begin{tabular}{lccc}
\hline \hline & Sex Ratio & Percentage Spent in Family Policies & Female Activity Rate \\
\hline Denmark & 102.47 & 12.80 & 84.28 \\
Finland & 105.12 & 12.56 & 84.64 \\
The Netherlands & 102.20 & 4.49 & 73.22 \\
The United Kingdom & 105.49 & 8.13 & 75.95 \\
Germany & 105.21 & 9.76 & 76.28 \\
Belgium & 104.53 & 8.90 & 74.59 \\
France & 105.84 & 9.84 & 79.19 \\
Austria & 107.08 & 10.47 & 77.33 \\
Italy & 106.39 & 3.61 & 59.13 \\
Ireland & 101.33 & 13.19 & 62.83 \\
Spain & 104.21 & 2.39 & 62.50 \\
Portugal & 107.41 & 5.26 & 78.40 \\
Greece & 101.96 & 7.98 & 62.26 \\
\hline European Countries & 104.79 & 7.50 & 71.62 \\
\hline \hline
\end{tabular}

Notes: ${ }^{1}$ The Sex Ratio is defined as the number of women per 100 men, Percentage spent in Family Policies refer to the percentage spent in family policies out of total public expenditure. Source for these variables is Eurostat (2007) ${ }^{2}$ Standard errors in parenthesis ${ }^{3}$ Countries are ordered from less to more traditional social norms regarding the household division of labor 
Table 6: The Effect of Social Norms Regarding the Household Division of Labor on the Probability of Having ever Been in a Partnership by Education Level Controlling FOR COUntry VARYing FACTORS ${ }^{1,2,3}$

\begin{tabular}{|c|c|c|c|c|c|}
\hline & $(1)$ & $(2)$ & $(3)$ & $(4)$ & $(5)$ \\
\hline traditionality index & $\begin{array}{c}-2.5498^{* * *} \\
(0.8841)\end{array}$ & $\begin{array}{c}-2.0847^{* *} \\
(0.9248)\end{array}$ & $\begin{array}{c}-2.8618^{* * *} \\
(0.9157)\end{array}$ & $\begin{array}{c}-2.5549^{* * *} \\
(0.8852)\end{array}$ & $\begin{array}{c}-2.4030^{* *} \\
(0.9496)\end{array}$ \\
\hline traditionality index $*$ low education level & $\begin{array}{c}2.9916^{* * *} \\
(0.6007)\end{array}$ & $\begin{array}{c}2.9641^{* * * *} \\
(0.6006)\end{array}$ & $\begin{array}{c}3.0058^{* * *} \\
(0.6010)\end{array}$ & $\begin{array}{c}2.9911^{* * *} \\
(0.6008)\end{array}$ & $\begin{array}{c}2.9781^{* * * *} \\
(0.6008)\end{array}$ \\
\hline traditionality index $*$ medium education level & $\begin{array}{c}2.9532^{* * *} \\
(0.5481)\end{array}$ & $\begin{array}{c}2.9909^{* * * *} \\
(0.5486)\end{array}$ & $\begin{array}{c}2.9386^{* * *} \\
(0.5483)\end{array}$ & $\begin{array}{c}2.9537^{* * *} \\
(0.5482)\end{array}$ & $\begin{array}{c}2.9771^{* * * *} \\
(0.5487)\end{array}$ \\
\hline age & $\begin{array}{c}0.0692^{* * *} \\
(0.0132)\end{array}$ & $\begin{array}{c}0.0692^{* * * *} \\
(0.0132)\end{array}$ & $\begin{array}{c}0.0692^{* * *} \\
(0.0132)\end{array}$ & $\begin{array}{c}0.0692^{* * *} \\
(0.0132)\end{array}$ & $\begin{array}{c}0.0692^{* * *} \\
(0.0132)\end{array}$ \\
\hline age2 & $\begin{array}{c}-0.0216^{* * *} \\
(0.0025)\end{array}$ & $\begin{array}{c}-0.0216^{* * * *} \\
(0.0025)\end{array}$ & $\begin{array}{c}-0.0216^{\text {*** }} \\
(0.0025)\end{array}$ & $\begin{array}{c}-0.0216^{* * *} \\
(0.0025)\end{array}$ & $\begin{array}{c}-0.0216^{* * *} \\
(0.0025)\end{array}$ \\
\hline medium education level & $\begin{array}{c}0.0012 \\
(0.0031)\end{array}$ & $\begin{array}{c}0.0006 \\
(0.0031)\end{array}$ & $\begin{array}{c}0.0015 \\
(0.0031)\end{array}$ & $\begin{array}{c}0.0012 \\
(0.0031)\end{array}$ & $\begin{array}{c}0.0009 \\
(0.0031)\end{array}$ \\
\hline high education level & $\begin{array}{c}0.0156^{* * *} \\
(0.0038)\end{array}$ & $\begin{array}{c}0.0151^{* * * *} \\
(0.0038)\end{array}$ & $\begin{array}{c}0.0158^{* * *} \\
(0.0038)\end{array}$ & $\begin{array}{c}0.0156^{* * *} \\
(0.0038)\end{array}$ & $\begin{array}{c}0.0152^{* * *} \\
(0.0038)\end{array}$ \\
\hline activity rate & $\begin{array}{l}- \\
-\end{array}$ & $\begin{array}{c}-0.0007^{* *} \\
(0.0003)\end{array}$ & $\begin{array}{l}- \\
-\end{array}$ & $\begin{array}{l}- \\
-\end{array}$ & $\begin{array}{c}-0.0007^{* *} \\
(0.0003)\end{array}$ \\
\hline sex ratio & - & $\begin{array}{l}- \\
-\end{array}$ & $\begin{array}{c}0.0044 \\
(0.0029)\end{array}$ & - & $\begin{array}{l}0.0050^{*} \\
(0.0029)\end{array}$ \\
\hline porc. help & $\begin{array}{l}- \\
-\end{array}$ & $\begin{array}{l}- \\
-\end{array}$ & $\begin{array}{l}- \\
-\end{array}$ & $\begin{array}{c}0.0002 \\
(0.0007)\end{array}$ & $\begin{array}{l}- \\
-\end{array}$ \\
\hline _cons & $\begin{array}{c}-1.5389^{* * *} \\
(0.5304)\end{array}$ & $\begin{array}{c}-1.4904^{* * *} \\
(0.5314)\end{array}$ & $\begin{array}{c}-1.9980^{* * *} \\
(0.6088)\end{array}$ & $\begin{array}{c}-1.5403^{* * *} \\
(0.5304)\end{array}$ & $\begin{array}{c}-2.0057^{* * *} \\
(0.6088)\end{array}$ \\
\hline Cohort dummies & Yes & Yes & Yes & Yes & Yes \\
\hline Country dummies & Yes & Yes & Yes & Yes & Yes \\
\hline Year dummies & Yes & Yes & Yes & Yes & Yes \\
\hline R sq. & 0.008 & 0.008 & 0.008 & 0.008 & 0.008 \\
\hline $\mathrm{N}$ & 121084 & 121084 & 121084 & 121084 & 121084 \\
\hline
\end{tabular}

Notes: ${ }^{1}$ The reported coefficients come from estimating a linear probability model on the probability to have ever been in a partnership ${ }^{2}$ Standard errors in parenthesis $3 * * *$ Significant at the $1 \%$ level **Significant at the $5 \%$ level $*$ Significant at the $10 \%$ level 
Table 7: Probability of Having ever Been in a Partnership: Other Robust Checks ${ }^{1,2,3}$,

\begin{tabular}{|c|c|c|c|c|c|}
\hline & $(1)$ & $(2)$ & $(3)$ & $(4)$ & $(5)$ \\
\hline \multicolumn{6}{|l|}{ Time trend instead of time dummies } \\
\hline traditionality index & $\begin{array}{c}-16.1707^{* * *} \\
(1.4096)\end{array}$ & $\begin{array}{c}-17.2156^{* * *} \\
(1.4221)\end{array}$ & $\begin{array}{l}-1.5418 \\
(3.3255)\end{array}$ & $\begin{array}{c}-10.9916^{* * *} \\
(3.5181)\end{array}$ & $\begin{array}{c}-2.3431^{* * *} \\
(0.8553)\end{array}$ \\
\hline traditionality index $*$ low education level & $\begin{array}{c}11.8774^{* * *} \\
(1.2635)\end{array}$ & $\begin{array}{c}11.9991^{* * *} \\
(1.2620)\end{array}$ & $\begin{array}{c}12.3330^{* * *} \\
(1.2854)\end{array}$ & $\begin{array}{c}12.3658^{* * * *} \\
(1.2844)\end{array}$ & $\begin{array}{c}2.8996^{* * *} \\
(0.5981)\end{array}$ \\
\hline traditionality index $*$ medium education level & $\begin{array}{c}11.5110^{* * *} \\
(1.5549)\end{array}$ & $\begin{array}{c}11.4912^{* * *} \\
(1.5540)\end{array}$ & $\begin{array}{c}12.3713^{* * *} \\
(1.5460)\end{array}$ & $\begin{array}{c}12.4887^{* * *} \\
(1.5462)\end{array}$ & $\begin{array}{c}2.8847^{* * *} \\
(0.5459) \\
\end{array}$ \\
\hline \multicolumn{6}{|l|}{ Sample of women between 30 and 50 years of age } \\
\hline traditionality index & $\begin{array}{c}-14.7460^{* * *} \\
(1.1851)\end{array}$ & $\begin{array}{c}-15.5136^{* * *} \\
(1.1970)\end{array}$ & $\begin{array}{l}-3.4620 \\
(2.8745)\end{array}$ & $\begin{array}{c}-9.3194^{* * *} \\
(3.1315)\end{array}$ & $\begin{array}{c}-1.6743^{* *} \\
(0.7118)\end{array}$ \\
\hline traditionality index $*$ low education level & $\begin{array}{c}11.0295^{* * *} \\
(1.0538)\end{array}$ & $\begin{array}{c}11.2125^{* * *} \\
(1.0544)\end{array}$ & $\begin{array}{c}11.3047^{* * *} \\
(1.0706)\end{array}$ & $\begin{array}{c}11.4206^{* * *} \\
(1.0714)\end{array}$ & $\begin{array}{c}2.0967^{* * * *} \\
(0.4750)\end{array}$ \\
\hline traditionality index $*$ medium education level & $\begin{array}{c}10.5358^{* * *} \\
(1.3224)\end{array}$ & $\begin{array}{c}10.5564^{* * *} \\
(1.3225)\end{array}$ & $\begin{array}{c}11.4192^{* * *} \\
(1.3171)\end{array}$ & $\begin{array}{c}11.5393^{* * *} \\
(1.3183)\end{array}$ & $\begin{array}{c}2.1529 * * * \\
(0.4442) \\
\end{array}$ \\
\hline \multicolumn{6}{|l|}{ Sample of women between 25 and 50 years of age } \\
\hline traditionality index & $\begin{array}{c}-28.1775^{* * *} \\
(1.1382)\end{array}$ & $\begin{array}{c}-29.2232^{* * *} \\
(1.1448)\end{array}$ & $\begin{array}{l}-4.3268 \\
(2.9001)\end{array}$ & $\begin{array}{c}-11.8587^{* * * *} \\
(3.1279)\end{array}$ & $\begin{array}{c}-1.5128^{*} \\
(0.8234)\end{array}$ \\
\hline traditionality index $*$ low education level & $\begin{array}{c}16.5362^{* * *} \\
(1.0249)\end{array}$ & $\begin{array}{c}16.7734^{* * *} \\
(1.0254)\end{array}$ & $\begin{array}{c}18.1673^{* * *} \\
(1.0395)\end{array}$ & $\begin{array}{c}18.3198^{* * *} \\
(1.0407)\end{array}$ & $\begin{array}{c}2.4693^{* * *} \\
(0.5625)\end{array}$ \\
\hline traditionality index $*$ medium education level & $\begin{array}{c}9.8193^{* * *} \\
(1.2803) \\
\end{array}$ & $\begin{array}{c}9.8367^{* * *} \\
(1.2811)\end{array}$ & $\begin{array}{c}10.7694^{* * *} \\
(1.2822)\end{array}$ & $\begin{array}{c}10.9164^{* * *} \\
(1.2834)\end{array}$ & $\begin{array}{c}1.7787^{* * *} \\
(0.5195) \\
\end{array}$ \\
\hline \multicolumn{6}{|l|}{ Egalitarian Index using a random sample } \\
\hline traditionality index & $\begin{array}{c}-15.8182^{* * *} \\
(1.3940)\end{array}$ & $\begin{array}{c}-16.9068^{* * *} \\
(1.4083)\end{array}$ & $\begin{array}{l}-4.4786 \\
(3.0766)\end{array}$ & $\begin{array}{c}-12.7065^{* * *} \\
(3.3539)\end{array}$ & $\begin{array}{c}-2.8226^{* * *} \\
(0.7990)\end{array}$ \\
\hline traditionality index $*$ low education level & $\begin{array}{c}11.9013^{* * *} \\
(1.2538)\end{array}$ & $\begin{array}{c}12.0346^{* * *} \\
(1.2531)\end{array}$ & $\begin{array}{c}12.4705^{* * *} \\
(1.2769)\end{array}$ & $\begin{array}{c}12.5209^{* * *} \\
(1.2765)\end{array}$ & $\begin{array}{c}2.9224^{* * *} \\
(0.5933)\end{array}$ \\
\hline traditionality index $*$ medium education level & $\begin{array}{c}11.4356^{* * *} \\
(1.5418)\end{array}$ & $\begin{array}{c}11.4843^{* * *} \\
(1.5412)\end{array}$ & $\begin{array}{c}12.3256^{* * *} \\
(1.5323)\end{array}$ & $\begin{array}{c}12.5140^{* * *} \\
(1.5332)\end{array}$ & $\begin{array}{c}2.9432^{* * *} \\
(0.5434) \\
\end{array}$ \\
\hline \multicolumn{6}{|l|}{ Self-reported health and labour status } \\
\hline traditionality index & $\begin{array}{c}-17.1551^{* * *} \\
(1.4757)\end{array}$ & $\begin{array}{c}-17.9969^{* * * *} \\
(1.4941)\end{array}$ & $\begin{array}{l}-2.6860 \\
(3.3992)\end{array}$ & $\begin{array}{c}-10.3659^{* * * *} \\
(3.7315)\end{array}$ & $\begin{array}{c}-2.7105^{* * *} \\
(0.9398)\end{array}$ \\
\hline traditionality index $*$ medium education level & $\begin{array}{c}11.8353^{* * *} \\
(1.6316)\end{array}$ & $\begin{array}{c}11.8245^{* * *} \\
(1.6322)\end{array}$ & $\begin{array}{c}13.0558^{* * *} \\
(1.6134)\end{array}$ & $\begin{array}{c}13.1738^{* * *} \\
(1.6156)\end{array}$ & $\begin{array}{c}3.0829^{* * *} \\
(0.6174)\end{array}$ \\
\hline traditionality index $*$ low education level & $\begin{array}{c}13.3603^{* * *} \\
(1.3560)\end{array}$ & $\begin{array}{c}13.4359^{* * *} \\
(1.3558)\end{array}$ & $\begin{array}{c}11.4823^{* * *} \\
(1.3794)\end{array}$ & $\begin{array}{c}11.5142^{* * *} \\
(1.3795)\end{array}$ & $\begin{array}{c}3.2456^{* * * *} \\
(0.6825)\end{array}$ \\
\hline
\end{tabular}

Notes: ${ }^{1}$ The reported coefficients come from estimating a linear probability model on the probability to have ever been in a partnership ${ }^{2}$ Standard errors in parenthesis $3 * * *$ Significant at the $1 \%$ level $* *$ Significant at the $5 \%$ level $*$ Significant at the $10 \%$ level. Self-reported health status is valued with the question "how is your health in general", with the following responses: Very good (1), Good (2), Fair (3), Bad (4), Very bad (5). Labour status variables indicate if the woman is working (1) or not(0), is working full-time (1) or not (0), and is self-employed (1) or not(0) 